\title{
Cytochemical Localization of Fungal Wall Components in Host-Pathogen Interactions: Particular Labeling with Gold-complexed Probes
}

\author{
G. B. Ouellette*, R. P. Baayen**, H. Chamberland***, M. Simard* and P. M. Charest*** \\ *Canadian Forest Service, Laurentian Forestry Centre, Quebec, Canada \\ **Plant Protection Institute, Wageningen, The Netherlands \\ ***Universite Laval, Health and Life Sciences Research Building, Quebec, QC, Canada
}

Gold-complexed lectins, mostly WGA, and enzymes are currently used to localize fungal wall components. Labeling for chitin is generally associated with the lucent wall layer, and erratic labeling is paralleled by irregularities in the wall layer [1]. Concentrations of gold particle occurrence close to fungal cells have also been observed suggesting that chitin components may be liberated into the surrounding medium. When using gold-complexed rabbit polyclonal antibodies to fungal compounds, control tests with pre-immune serum have often shown that the probe strongly attached to fungal cell walls, indicating that using concomitantly such a test is essential. Without it, however, the results obtained with the antibody may still be informative. For example, tests with a labeled polyclonal antibody to fungal fimbriae to identify extracellular structures produced by Phaeotheca dimorphospora showed that the probe attached to components in the medium at a distance from the fungal colony; these were similar to structures marginating the fungal cell (Figs 1, 2). As this fungus inhibits other fungal plant pathogens [2], and as a compound obtained from the agar medium distally from the fungal colony is strongly inhibitory as well to a fungal human pathogen (L. Giasson, Universite Laval, unpublished), these labeling results may be meaningful.

Another peculiar result was obtained using a gold-complexed monoclonal antibody (mab) against esterified pectin in histopathological studies of infection by Fusarium oxysporum f.sp. dianthi, causing a wilt in carnation. Walls of fungal cells, even of endocells, clearly labeled with the probe (Fig. 3), which was shown in the same tests, to bind specifically to host plant cell walls. As questioned by Chamberland [3] the labeling in such cases might not have been indicative of a fungal wall component. Indeed, subsequent similar tests with the fungus in culture gave negative results. However, by growing the fungus on an agar medium supplied with citrus pectin, this substrate was found to bind closely to the fungal wall (Fig. 4), indicating that in the infected plant, pectin residues might have been fully adsorbed by the fungus cell walls. As fungal walls in susceptible plants generally labeled less strongly than in resistant plants, these results may have a bearing on our understanding of the host-pathogen relationships in this disease.

References

[1] G.B. Ouellette et al. 2001. Chitin Enzymology. Atec Edizioni, Grottamare, Italy. 79-89.

[2] D. Yang et al. 1993. Can. J. Bot. 71:426.

[3] H. Chamberland. 1994. Host Wall Alterations by Parasitic Fungi. APS Press. pp 1-11. 


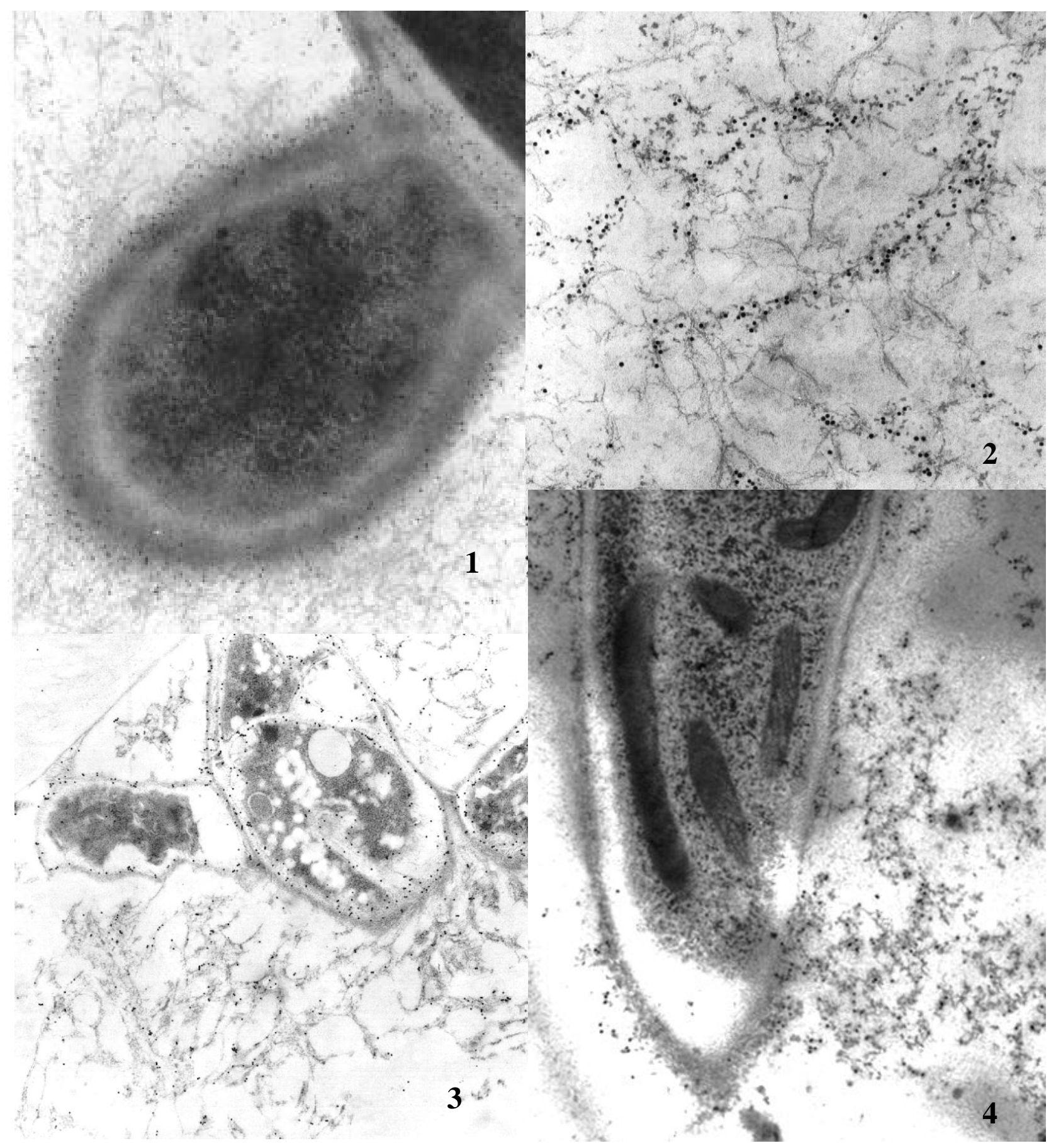

FIGS 1, 2. Phaeotheca dimorphospora. Labeling with polyclonal antifimbriae (kindly furnished by Dr. A Day, Univ. Western Ontario). FIG. 1 Outside layer of fungal cells contains labeled fimbriae extending into the surrounding medium. FIG. 2. Labeling is concentrated on the more compact patches of amorphous material, bordered by more fibrillar matter which extended some distance from the fungal cells into the medium. FIGS 3, 4. Fusarium oxysporum f. sp. dianthi. Labeling with mab to esterified pectin (JIM 5). FIG. 3. Walls of altered fungal cells and fibrillar material nearby, in vessel lumen, are well labeled. FIG. 4. Walls of fungal cell in culture containing pectin components, are not labeled, except sparsely where the pectin substrate contacts the fungus wall. 